PIWULANG: Jurnal Pendidikan Agama Islam, Vol. 3 No. 2 Maret 2021, 157-172

P-ISSN : 2622-5638. E-ISSN : 2622-5654

Homepage: http://e-journal.staima-alhikam.ac.id/index.php/piwulang

\title{
RELEVANSI PEMIKIRAN PENDIDIKAN IBN KHALDUN DI INDONESIA
}

\author{
Oleh: \\ Mutamakin (1) \& M. Yusuf Agung Subekti (2) \\ (1)(2) STAI Ma'had Aly Al Hikam Malang - Indonesia \\ Email:mt.makkin@gmail.com \\ Email: yusembon@gmail.com
}

\begin{abstract}
Ibn Khaldun is a Muslim scholar who was born in Tunisia, North Africa, in 1332 $A D$. Ibn Khaldun's contribution to the understanding of civilization and sociology is so rich and important that it is still relevant today. This paper seeks to explore Ibn Khaldun's work in particular his ideas about education in the Muqaddimah book and then investigates the extent of its contemporary relevance, particularly in the curriculum of teacher education programs in Indonesia. Ibn Khaldun provides a long and detailed discussion of the concepts of education and pedagogy in Chapter Six of the Muqaddimah. His knowledge classification served as a guideline for the various sciences that existed at that time. He also gave his views on teaching and learning issues. The final section of this paper looks at the nature of curricula in current teacher education programs and considers developing a more inclusive approach.
\end{abstract}

\section{ABSTRAK}

Ibn Khaldun adalah seorang sarjana Muslim yang lahir di Tunisia, Afrika Utara, pada tahun 1332M. Kontribusi Ibn Khaldun terhadap pemahaman peradaban dan sosiologi begitu kaya dan penting sehingga masih relevan hingga saat ini. Tulisan ini berupaya mengeksplorasi karya Ibn Khaldun khususnya ide-idenya tentang pendidikan dalam kitab Muqaddimah dan kemudian menyelidiki sejauh mana relevansi kontemporernya, khususnya dalam kurikulum program pendidikan guru di Indonesia. Ibn Khaldun memberikan pembahasan panjang dan rinci tentang konsep pendidikan dan paedagogi dalam Bab Enam Muqaddimah. Klasifikasi ilmunya menjadi pedoman bagi berbagai ilmu yang ada saat itu. Dia juga memberikan pandangannya tentang masalah pengajaran dan pembelajaran. Bagian terakhir dari makalah ini melihat sifat kurikulum dalam program pendidikan guru saat ini dan mempertimbangkan pengembangan pendekatan yang lebih inklusif.

KATA KUNCI: Ibn Khaldun, Muqaddimah, Kurikulum Pendidikan Guru 
PIWULANG: Jurnal Pendidikan Agama Islam, Vol. 3 No. 2 Maret 2021, 157-172

P-ISSN : 2622-5638. E-ISSN : 2622-5654

Homepage: http://e-journal.staima-alhikam.ac.id/index.php/piwulang

\section{A. PENGANTAR}

Ibnu Khaldun diakui sebagai ilmuwan Islam pertama yang menulis tentang teori Sosiai, dan sebagai perintis ilmu Sosiologi. Raewyn Connell dalam bukunya "Southern Theory" (2007) tentang dinamika global ilmu pengetahuan sosial, berpendapat bahwa tulisan Ibn Khaldun dapat dikategorikan sebagai ungkapan 'universalisme alternatif'. ${ }^{1}$ Maksudnya, pemikiran Ibnu Khaldun tentang metode penelitian dan pentingnya keadilan dan hak asasi manusia dalam masyarakat, dapat diterapkan dalam masyarakat di mana pun, meskipun mereka berasal dari bagian selatan biner geografis perkembangan pengetahuan.

Makalah ini berupaya mengungkap apakah gagasan Ibn Khaldun tentang pendidikan juga dapat dianggap memiliki makna universal. Pendekatan dalam makalah ini terdiri atas dua tahap: pertama, tinjauan terhadap gagasan Ibn Khaldun tentang pendidikan, terutama dalam Bab Enam dari karyanya Muqaddimah, dan kedua, penyelidikan untuk memastikan sejauh mana penerapan ide-ide pendidikannya untuk pendidikan guru. ertanyaan mendasar dalam penelitian ini adalah: Aspek apa dari gagasan Ibn Khaldun tentang pendidikan, yang ditulis pada abad pertengahan dari perspektif Islam, yang relevan dengan program pendidikan guru kontemporer?

Mengingat kehadiran komunitas Islam sebagai bagian integral dari masyarakat multikultural, pertanyaan penelitian memiliki relevansi yang lebih langsung dan tajam. Namun, agar tulisan-tulisan pendidikan Ibn Khaldun memiliki makna universal, tulisan-tulisan itu perlu dibuktikan relevan dengan masyarakat kontemporer, serta komunitas Islam sendiri.

\section{B. METODE DAN PENDEKATAN}

Tulisan ini merupakan hasil penelitian pustaka (library research) dengan menggunakan pendekatan kualitatif. Penulis dalam hal ini berupaya mengumpulkan data-data kepustakaan terkait pemikiran Ibnu Khaldun dalam bidang pendidikan Islam baik melalui buku-buku ataupun sumber lain seperti artikel atau penelitian-penelitian terdahulu yang terkait dengan topik tersebut. Data yang terkait dengan konsep pendidikan Islam Ibnu

\footnotetext{
${ }^{1}$ Connell, Raewyn. (2007). Southern Theory: The Global Dynamics Of Knowledge In Social Science. Cambridge: Polity Press.
} 
PIWULANG: Jurnal Pendidikan Agama Islam, Vol. 3 No. 2 Maret 2021, 157-172

P-ISSN : 2622-5638. E-ISSN : 2622-5654

Homepage: http://e-journal.staima-alhikam.ac.id/index.php/piwulang

Khaldun kemudian dianalisis untuk menentukan tema-tema yang terkait dengan konsep pendidikan Islam dalam perspektif Ibnu Khaldun.

Pendekatan yang diadopsi dalam makalah ini adalah untuk memperkenalkan Ibn Khaldun dan pemikiran pendidikannya dan kemudian mengeksplorasi kemungkinan signifikansi dan relevansi ide-idenya untuk program pendidikan guru saat ini. Ini bertujuan untuk mencapai tujuantujuan pendidikan melalui penjelasan rinci dan deskriptif dari cendekiawan/cendekiawan Islam yang kurang diakui dalam kesarjanaan pendidikan Barat. Pendekatan deskriptif yang diadopsi dalam makalah ini dimaksudkan untuk mengundang peneliti lain untuk mengapresiasi beberapa pemikirannya dan kemudian memanfaatkannya untuk analisis pendidikan mereka sendiri. Pendekatan ini lebih cocok untuk mengapresiasi karya-karya warisan sejarah, agama dan budaya yang berbeda dan menilai sejauh mana ide-ide yang diungkapkan memiliki makna universal bagi umat manusia yang melampaui konteks tertentu dari zamannya.

\section{HASIL DAN PEMBAHASAN a) Kehidupan dan Karya Ibn Khaldun}

Ibn Khaldun, atau untuk memberinya nama lengkap yang menguraikan latar belakang keluarganya, Waly al-Din 'Abd al-Rahman Ibn Muhammad Ibn Abi Bakr Muhammad Ibn al-Hasan Ibn Khaldun alMaliki al-Hadrami, lahir pada tahun 1332 M. untuk seorang yang berpengaruh. Keluarga Arab Muslim Sunni di Tunis (sekarang Tunisia), Afrika Utara, pada masa Kekaisaran Hafsid. Nenek moyang Ibn Khaldun berasal dari klan Arab Selatan yang disebut Kinda, berasal dari Yaman, tetapi mereka menetap di Seville, Andalusia, pada saat penaklukan Arab di Semenanjung Iberia. Beberapa detail latar belakang keluarganya membantu memberikan pemahaman tentang konteks di mana dia dibesarkan. Di antara nenek moyang Ibn Khaldun, Kurayb terkenal karena memberontak pada akhir abad kesembilan melawan dinasti Islam awal yang disebut Umayyah, yang berpusat di kota Cordoba di Spanyol, ${ }^{2}$ dan mendirikan sebuah negara merdeka di Seville. Tercatat bahwa Banu Khaldun, kakek buyut Ibn Khaldun, adalah seorang pemimpin politik terkemuka di Seville. Namun, kakek dan ayah Ibn Khaldun mengundurkan diri dari kehidupan politik dan bergabung

\footnotetext{
${ }^{2}$ Robinson, F. (1996). Knowledge its transforming the making of Muslim societies In F. Robinson (Ed.), The Cambridge illustrated history of the Islamic world. Cambridge, England Cambridge University Press.Robinson, 1996, h. 26-27
}

- $\quad$ Mutamakin \& M. Yusuf Agung- 159 
PIWULANG: Jurnal Pendidikan Agama Islam, Vol. 3 No. 2 Maret 2021, 157-172

P-ISSN : 2622-5638. E-ISSN : 2622-5654

Homepage: http://e-journal.staima-alhikam.ac.id/index.php/piwulang

dengan Tarekat Sufi. Saudaranya, Yahya Khaldun, adalah seorang sejarawan yang menulis buku tentang dinasti Abdalwadid atau dinasti Zayyanid. $^{3}$

Menurut Syed Farid Alatas (2006), sejak usia dini, Ibnu Khaldun mulai mempelajari Al-Qur'an, fikih madzhab Maliki, Hadis, syair dan teosofi tasawuf. Pada tahap awal ini, ayahnya adalah yang paling berpengaruh di antara guru-gurunya, mengenalkannya pada tasawuf dan mendorongnya untuk berfikir mandiri. ${ }^{4}$ Pendidikannya di kemudian hari lebih beragam; ia tidak belajar di satu lembaga tetapi mengikuti bimbingan beberapa guru yang bersedia menerimanya. Status sosial keluarganya yang tinggi memungkinkan Ibn Khaldun belajar dengan guru-guru terbaik di Maghreb. Yang terpenting dari guru-guru ini adalah Al-Abili, seorang ahli di bidang logika, matematika, dan filsafat. Al-Abili tidak percaya pada gagasan pendidikan yang diformalkan dan dilembagakan, seperti yang ditemukan dalam apa yang disebut sistem Madrasah, dia juga tidak mendukung kontrol negara atas lembaga-lembaga pendidikan. Pada tahap selanjutnya, pemikiran AlAbili tentang pendidikan dan institusi pendidikan memiliki pengaruh yang besar terhadap pemikiran Ibnu Khaldun tentang masalah tersebut, khususnya pedagogi. ${ }^{5}$

Karena dia belum dididik di bawah sistem Madrasah yang ada saat itu, Ibn Khaldun tidak diindoktrinasi melalui kontrol ketat atas pengetahuan, pengajaran dan gaya belajar. Al-Abili memperkenalkan Ibn Khaldun ilmu-ilmu matematika, logika dan filsafat, melalui studi karya ulama Islam seperti Ibnu Rusyd, Ibnu Sina, Ar-Razi dan Al-Tusi. Selain itu, Ibn Khaldun juga menghabiskan waktunya membaca bukubuku tulisan Plato, Aristoteles, dan karya-karya filsuf Yunani lain. Pemikiran filsafat Islam dan tulisan-tulisan Yunani memberinya inspirasi dalam petualangan akademis dan kegemarannya untuk penyelidikan kritis dan rasionalis. Karir Ibn Khaldun dalam politik memberinya perspektif unik dan wawasan kehidupan nyata yang dapat digunakan untuk menganalisis secara kritis studi sejarah, kekuasaan dan perubahan sosial. ${ }^{6}$

\footnotetext{
3 Abdulwadids: Abd al-Wadids, atau Zayyanids, adalah dinasti Berber Zenata yang memerintah kerajaan Tlemcem, sebuah wilayah di barat laut Aljazair dari 1235 hingga 1556 (Alatas, 2007; Ibn Khaldun, 1958b; Samarah, 2011)

${ }^{4}$ Ibn Khaldun. (1958b). The 'Muqaddimah': An Introduction to History, terjemah dari bahasa Arab oleh Rosenthal, F (Vol. VI). London: Routledge \& Kegan Paul.

${ }^{5}$ Ibn Khaldun, 1958b

${ }^{6}$ Alatas, S., F. (2012). Makers of Islamic Civilization: Ibn Khaldun, New Delhi: Oxford University Press.
}

- Mutamakin \& M. Yusuf Agung- 160 
PIWULANG: Jurnal Pendidikan Agama Islam, Vol. 3 No. 2 Maret 2021, 157-172

P-ISSN : 2622-5638. E-ISSN : 2622-5654

Homepage: http://e-journal.staima-alhikam.ac.id/index.php/piwulang

Pada usia muda 20 tahun, Ibn Khaldun menerima tawaran dari penguasa Tunis, Abu Ishaq II, untuk menduduki jabatan di istananya. Dengan kegemarannya berpetualang dan semangatnya untuk menjelajah, Ibnu Khaldun pindah ke kerajaan Maroko bernama Fez. Dia diangkat sebagai sekretaris negara untuk Sultan Abu-Inan dari Fez, di mana dia diangkat sebagai sekretaris negara Sultan Abu-Inan. Setelah beberapa saat di Fez, Ibn Khaldun pindah ke Selat Gibraltar. Di sini dia mengalami tanggung jawab besar pertamanya ketika dia terpilih menjadi Pemegang Tanah Sultan Granada. Sultan Granada juga mengirim Ibn Khaldun sebagai duta untuk bertemu Pedro (Peter), Raja Castille. Namun, setelah misi petualangan ini dan berbagai konflik politik lainnya, termasuk dengan Wazir di Granada, Ibn Khaldun kehilangan minat dalam politik. Setelah mencoba posisi lain, ia akhirnya diusir dari Spanyol pada tahun 1374 M. Di Afrika Utara di benteng Qilah-IbneSalamah itulah Ibn Khaldun menyelesaikan karyanya yang paling terkenal "Muqaddimah". Menurut Ibnu Khaldun, ia selesai menulis Muqaddimah pada November 1377M tapi pengerjaannya dilanjutkan sampai sesaat sebelum kematiannya. ${ }^{7}$

Pada tahun 1382M Ibn khaldun tinggal di Kairo. ${ }^{8}$ Dalam dua puluh tahun sisa hidupnya, ia memiliki kesempatan untuk mempraktikkan gagasannya tentang pendidikan dengan mengajar di berbagai perguruan tinggi agama di kota itu. Tampaknya pendekatannya dalam mengajar menarik bagi siswa. Menurut Mussallam 'siswa berbondong-bondong mengikuti kuliahnya'. ${ }^{9}$ Apalagi karena keberhasilan pengajarannya, Ibn Khaldun menimbulkan 'permusuhan cemburu dari cendekiawan Mesir lokal'. Akhirnya dia diangkat sebagai hakim agung, sebelum dia meninggal pada 1406 di Kairo. ${ }^{10}$

Karya ilmiah Ibn Khaldun mencakup berbagai manuskrip dan kitab, yang paling menonjol di antaranya adalah Muqaddimah, yang dikenal sebagai Prolegomena, atau Pengantar, Kitab al-Ibar wa Diwan alMubtada wa al-Khabar fi Ayyam al-Ajam wa al-Barbar wa man Asaraham min Dhawi al-Sultan al-Akbar (Kitab Contoh dan Kumpulan Asal Usul Sejarah Bangsa Arab dan Berber). Buku pertamanya, Lababu I-Muhassal fi ushul al-din (Rangkuman Kumpulan Ushuluddin) adalah komentar

\footnotetext{
${ }^{7}$ Alatas, 2012; Ibnu Khaldun, 1958b

${ }^{8}$ Irwin, R. (1996). Munculnya Sistem Dunia Islam 1000-1500M. Dalam F. Robinson (Ed.), Cambridge Illustrated History of the Islamic World (hlm. 32-61). Cambridge: Cambridge University Press. h. 35

${ }^{9}$ Alatas, 2012

${ }^{10}$ Alatas, 2012
}

- $\quad$ Mutamakin \& M. Yusuf Agung- 161 
PIWULANG: Jurnal Pendidikan Agama Islam, Vol. 3 No. 2 Maret 2021, 157-172

P-ISSN : 2622-5638. E-ISSN : 2622-5654

Homepage: http://e-journal.staima-alhikam.ac.id/index.php/piwulang

tentang teologi ar-Razi, yang ditulisnya pada usia 19 di bawah pengawasan gurunya, al-Alibi, di Tunis. Sebuah karya tentang tasawuf, Sifa 'u I-Sa'il, disusun sekitar tahun 1373 di Fez. Sementara di istana Muhammad V, Sultan Granada, Ibn Khaldun menyelesaikan karya logika, Allaqqa li-I-Sultan. Autobiografi yang ditulisnya berjudul, Al-Ta'rif bi Ibn Khaldun wa Rihlatuhu Gharban wa Sharqan (Biografi Ibn Khaldun dan Perjalanannya ke Timur dan Barat). ${ }^{11}$

Tinjauan sejarah singkat tentang kehidupan dan tulisan Ibn Khaldun ini memberikan pemahaman dasar tentang pendidikan pribadinya dan karya ilmiahnya. Bagian selanjutnya berfokus pada gagasan pendidikan yang terdapat dalam Muqaddimah.

\section{b) Dasar Pemikiran Pendidikan Ibn Khaldun}

Dalam Bab Enam dari "Muqaddimah", Ibn Khaldun membahas pemikirannya tentang pendidikan dalam tiga judul: Macam-macam ilmu; Metode pengajaran; Kondisi yang didapat dalam koneksi ini'. Ideide ini tidak mewakili filsafat pendidikan yang berkembang sepenuhnya, melainkan dapat dilihat sebagai refleksi dari pendekatan pengajaran yang menurutnya penting untuk mendorong siswa agar dapat belajar dengan baik. Tulisannya dikembangkan dari dua sumber. Sumber pertama adalah pengalaman belajar pribadinya yang beragam, yang terbukti positif, memperkaya dan seumur hidup melalui perjalanannya, tetapi tidak pernah menempuh pendidikan sekolah madrasah formal mana pun. Rosenthal, dalam pengantarnya pada edisi bahasa Inggris dari "Muqaddimah", mengemukakan bahwa 'banyak dari materinya dan banyak dari ide-ide terbaiknya yang dimiliki Ibn Khaldun kepada gurugurunya, teman-teman siswa dan kolega pasti telah memberikan kontribusi yang besar terhadap pengetahuannya'. ${ }^{12}$ Sumber kedua dari ide-idenya adalah pengamatannya mengajar di kelas-kelas Madrasah yang telah dia kunjungi di banyak tempat yang pernah dia tinggali. Dia telah membentuk opini yang sangat buruk tentang pengajaran semacam itu dan tentang pengalaman negatif belajar yang ditimbulkannya bagi para siswa.

Menurut bab Enam Muqaddimah, sistem pendidikan masyarakat mana pun harus dirumuskan menurut ideologinya. Ibn Khaldun sangat menganjurkan bahwa setiap pria dan wanita Muslim harus mengetahui Al-Qur'an dan Sunnah dan mengikuti petunjuk Allah, seperti yang

${ }^{11}$ Tjandrasasmita, U. (2006). Kajian naskah-naskah sejarah klasik dan penerapannya bagi kajian Islam di Indonesia. Jakarta: Puslitbang Lektur Keagamaan.

${ }^{12}$ Ibn Khaldun, 1958a, h.. IXXXV

- $\quad$ Mutamakin \& M. Yusuf Agung- 162 
PIWULANG: Jurnal Pendidikan Agama Islam, Vol. 3 No. 2 Maret 2021, 157-172

P-ISSN : 2622-5638. E-ISSN : 2622-5654

Homepage: http://e-journal.staima-alhikam.ac.id/index.php/piwulang

diajarkan oleh Nabi. 'Mengajar anak-anak Al-Qur'an adalah simbol Islam. Muslim mempraktikkan pembinaan seperti itu di semua tempat tinggal mereka, karena itu mengilhami hati dengan keyakinan dan keimanan Islam yang kuat'. ${ }^{13}$ Prinsip agama yang fundamental seperti itu membuat tulisan-tulisan pendidikan Ibn Khaldun sangat sesuai dalam komunitas Islam.

\section{c) Klasifikasi Ilmu}

Klasifikasi ilmu dalam konteks Islam, sebagaimana dikemukakan oleh Ibnu Khaldun, memberikan pemahaman historis yang baik tentang produksi ilmu dan klasifikasi ilmu yang ada pada saat itu. Dalam Islam, sains dianggap sebagai kesatuan dan termasuk dalam tatanan hierarkis. Ibn Khaldun menjelaskan pengelompokannya menjadi dua kelompok, yang pertama adalah ilmu-ilmu filosofis yang bertumpu pada kemampuan berpikir manusia. Ini melibatkan kemampuan untuk memecahkan masalah, membangun dan melawan argumen, dan mengembangkan metode pengamatan sistematis berdasarkan persepsi manusia. Contoh ilmu filsafat yang diberikan oleh Ibn Khaldun termasuk Ilmu logika, fisika, ilmu kealaman, zoologi, botani, kimia, mineral, ilmu atmosfer, seismologi, psikologi, kedokteran, pertanian, metafisika, matematika, geometri, aritmatika, musik dan astronomi. ${ }^{14}$

Jenis ilmu kedua, yang oleh Ibnu Khaldun disebut sebagai ilmu tradisional, bersumber dari otoritas agama melalui proses wahyu. Meskipun kecerdasan manusia memiliki peran dalam sains tradisional, karakter dasar pengetahuan tetap tidak berubah dalam bentuk pengungkapannya. Contoh yang dia berikan adalah Ilmu Al-Qur'an, Ilmu bahasa Arab, leksikografi, tata bahasa, sintaksis, sastra, ilmu tradisi kenabian, fiqih dan prinsip-prinsipnya, teologi spekulatif, tasawuf dan ilmu tafsir mimpi. ${ }^{15}$

Meskipun Ibn Khaldun mengakui adanya sumber ketiga ilmu yang disebut ilmu ghaib, yang meliputi 'ilmu sihir, sihir huruf, rajah dan jimat' (Alatas, 2012) ia tidak memasukkan ini dalam pembahasannya tentang pendidikan, karena ilmu tersebut dilarang oleh hukum agama.

Penjelasan tentang pendidikan di awal Bab Enam Muqaddimah ini memberikan dasar bagi pandangan Ibn Khaldun tentang berbagai masalah pendidikan dan pengajaran lainnya. Klasifikasi

${ }^{13}$ Ibn Khaldun, 1958b, h 300

${ }^{14}$ Alatas, 2012, h.83

${ }^{15}$ Alatas, 2012, h. 83

- $\quad$ Mutamakin \& M. Yusuf Agung- 163 
PIWULANG: Jurnal Pendidikan Agama Islam, Vol. 3 No. 2 Maret 2021, 157-172

P-ISSN : 2622-5638. E-ISSN : 2622-5654

Homepage: http://e-journal.staima-alhikam.ac.id/index.php/piwulang

pengetahuannya, berdasarkan konteks pendidikan Islam, sangat relevan dan penting. ${ }^{16}$

\section{d) Pandangan Ibn Khaldun tentang Makna Pendidikan yang Lebih Luas}

Dalam pembahasannya tentang hakikat pendidikan dan signifikansinya bagi individu dan masyarakat, gagasan Ibn Khaldun dapat dilihat memiliki penerapan yang lebih luas. Dia menekankan, misalnya, pentingnya pendidikan dalam mengembangkan daya pikir dan penalaran individu. Dalam pandangannya, 'kemampuan berpikir' adalah yang membedakan 'manusia dari hewan' dan memungkinkan manusia 'untuk mendapatkan mata pencahariannya dan bekerjasama untuk tujuan ini dengan sesama manusia. Untuk membuktikan kemanfaatan pendidikan bagi masyarakat, Ibn Khaldun percaya bahwa pendidikan harus mengembangkan efisiensi sosial dan ekonomi pada individu agar mereka bisa berkiprah dan berperan penting dalam masyarakat. Seorang Individu juga harus membawa dampak positif ke dalam kehidupan orang-orang sekitarnya.

Dari pengalaman pribadinya, ia percaya berkelana (study tour) adalah cara yang penting untuk terus mendapatkan ilmu dan memperluas pendidikan pribadi melalui pembelajaran dari berbagai ulama di seluruh dunia. ${ }^{17}$ Keterbukaan terhadap ide-ide baru dan kemungkinan interaksi dan diskusi yang berkelanjutan dengan guru merupakan elemen penting dalam pemikirannya tentang pendidikan. Dalam pandangannya, 'manusia memperoleh kebajikan mereka baik melalui studi, instruksi dan ceramah, atau melalui peniruan (imitating) seorang guru dan kontak pribadi dengannya. Perbedaan study tour dengan lainnya adalah bahwa kebiasaan yang diperoleh melalui kontak pribadi dengan seorang guru lebih melekat dan berakar kuat'.18

Pemikiran pendidikan Ibn Khaldun dengan demikian dapat dilihat fokus pada manfaat pribadi yang menurutnya pendidikan yang baik harus diberikan kepada siswanya, tidak hanya dalam masa sekolah, tetapi sepanjang hidup mereka dalam keterbukaan terhadap ide dan pengalaman baru. Argumen dasarnya adalah pendidikan harus mencakup sosial dan moral, serta pembelajaran intelektual untuk memunculkan potensi dalam diri manusia melalui pengembangan karakter dan pembentukan kepribadian, bersamaan dengan

${ }^{16}$ Ibn Khaldun, 1958b

${ }^{17}$ Ibn Khaldun, 1958b

${ }^{18}$ Ibn Khaldun, 1958b, h. 307

- $\quad$ Mutamakin \& M. Yusuf Agung- 164 
PIWULANG: Jurnal Pendidikan Agama Islam, Vol. 3 No. 2 Maret 2021, 157-172

P-ISSN : 2622-5638. E-ISSN : 2622-5654

Homepage: http://e-journal.staima-alhikam.ac.id/index.php/piwulang

kemampuan bernalar. Nilai dan pentingnya gagasan pendidikan Ibn Khaldun ini tidak terbatas pada abad pertengahan atau pada masyarakat Islam saja. ${ }^{19}$

a) Pola Belajar dan Mengajar

Ibn Khaldun memiliki pandangan jelas tentang proses belajar mengajar, terutama terkait dengan kapasitas belajar, hafalan, kurikulum dan kedisiplinan guru. Dia mengamati hubungan antara pendidikan dan masyarakat dan percaya bahwa pendidikan memiliki berbagai tujuan. Berdasarkan pengamatannya tentang cara belajar terbaik siswa, Ibn Khaldun memandang bahwa prinsip-prinsip berikut penting untuk pendidikan yang baik. Pertama, ia percaya bahwa urutan pengenalan mata pelajaran menentukan keberhasilan hasil belajar. Ia juga percaya bahwa melimpahnya karya ilmiah menjadi kendala dalam belajar. Perkembangan buku pegangan yang menyediakan ringkasan merugikan pembelajaran. Studi tentang pengetahuan sains tambahan (yaitu, non-dasar) tidak boleh berkepanjangan. Hukuman berat tidak boleh dijatuhkan kepada siswa. ${ }^{20}$

Ibn Khaldun juga memiliki pandangan yang mapan tentang metode pengajaran untuk belajar. Menurutnya, pengajaran hanya menjadi efektif bila berlangsung lama dan bertahap. Tahapan utama dalam proses ini, menurut Ibnu Khaldun, guru harus memulai dengan pengenalan prinsip-prinsip dasar mata pelajaran. Kedua, guru harus mengamati dengan cermat kemampuan siswa untuk memahami apa yang telah diperkenalkan. Pada tahap ketiga, guru harus mengulang materi untuk kedua kalinya, mengajar di tingkat yang lebih tinggi. Alih-alih membuat ringkasan di akhir pelajaran, guru harus memberikan komentar dan penjelasan lengkap. Dengan cara ini, landasan siswa dalam disiplin ilmu menjadi lebih dalam. Guru kemudian dapat membawa siswa melalui materi pelajaran di lain waktu, berkaitan dengan materi pelajaran yang tidak jelas atau rumit. $^{21}$

Ibn Khaldun percaya bahwa pembelajaran yang efektif membutuhkan pengulangan tiga kali lipat. Dari pengamatannya, ia melihat bahwa banyak guru, terutama dalam konteks sekolah Madrasah saat itu, yang mengabaikan metode ini. Guru seperti itu

${ }^{19}$ Ibn Khaldun, $1958 b$

${ }^{20}$ Ibn Khaldun, 1958b

${ }^{21}$ Alatas, 2012; Ibn Khaldun, 1958b

- $\quad$ Mutamakin \& M. Yusuf Agung- 165 
PIWULANG: Jurnal Pendidikan Agama Islam, Vol. 3 No. 2 Maret 2021, 157-172

P-ISSN : 2622-5638. E-ISSN : 2622-5654

Homepage: http://e-journal.staima-alhikam.ac.id/index.php/piwulang

memperkenalkan siswa pada pembahasan ilmiah yang rumit sementara siswa belum siap. Siswa, terutama pada usia muda, hanya mampu memperoleh pemahaman yang sekilas dan umum dari pembahasan yang kompleks. ${ }^{22}$

Ibn Khaldun juga memberikan nasehat tentang masalahmasalah yang berkaitan dengan hukuman berat, terutama yang digunakan di Madrasah dan lembaga Pendidikan Islam lainnya, dan kegagalannya untuk membantu siswa dalam proses pembelajaran mereka. Dalam pandangannya, hukuman, terutama perlakuan yang kasar (fisik atau verbal), akan membuat siswa merasa lebih tertekan, menjadi malas, atau menjadi tidak jujur dan cenderung lebih sering melanggar peraturan. Di bagian ini, ia juga membahas interaksi dan hubungan siswa-guru, yang menurutnya sangat penting dalam proses pembelajaran siswa. Ibn Khaldun mengatakan bahwa hubungan antara guru dan murid harus dilandasi oleh cinta dan pengertian. Guru perlu memahami kemampuan belajar individu masing-masing siswanya dan bekerjasama dengan siswa secara dekat, sesuai dengan tahapan yang diuraikan dalam metode pengajarannya. ${ }^{23}$

b) Kurikulum

Ibn Khaldun memiliki pandangan yang sangat kritis terhadap modul dan buku teks yang digunakan di Madrasah dan sekolah lain di dunia Muslim pada saat itu. Menurutnya, sebagian besar modul dan buku teks tersebut sarat dengan penjelasan yang panjang dan terminologi yang rumit sehingga menyulitkan siswa untuk memahami isi yang sebenarnya. Selain itu, mereka tidak memberikan kesempatan kepada siswa untuk mengembangkan pemikiran mandiri. Pada saat yang sama, ia menganjurkan pengajaran agama sebagai landasan kurikulum karena membantu siswa membangun karakter dan akhlak mulia.

Aspek penting lainnya dalam kurikulum yang disoroti oleh Ibn Khaldun adalah berfikir yang jernih. Dia percaya bahwa logika memungkinkan seseorang untuk berpikir dan menganalisis secara kritis. Belajar matematika penting karena mengasah keterampilan mental dan meningkatkan daya nalar. Ibn Khaldun juga menekankan pembelajaran bahasa karena ini membantu siswa mempelajari mata pelajaran yang berbeda dengan lebih efektif. Selain itu, ia menilai

${ }^{22}$ Alatas, 2012; Ibn Khaldun, 1958b

${ }^{23}$ S. Alatas, F, 2012; Ibn Khaldun, 1958b; Tjandrasasmita, 2006

- $\quad$ Mutamakin \& M. Yusuf Agung- 166 
PIWULANG: Jurnal Pendidikan Agama Islam, Vol. 3 No. 2 Maret 2021, 157-172

P-ISSN : 2622-5638. E-ISSN : 2622-5654

Homepage: http://e-journal.staima-alhikam.ac.id/index.php/piwulang

bahwa mata pelajaran profesi dan vokasi perlu dimasukkan dalam kurikulum bersama dengan kajian akademis. ${ }^{24}$

Dalam kaitannya dengan pembelajaran bahasa, Ibnu Khaldun menilai bahwa bahasa apapun harus dipelajari dengan cara yang natural, mengingat kompetensi tidak datang secara otomstis dan langsung, tetapi secara bertahap. Dia percaya bahwa kompetensi bahasa dapat bervariasi antara ketrampilan berbicara dan menulis dan tidak perlu secara tepat menerapkan aturan tata bahasa dan sintaksis. Namun, dia bersikeras bahwa siswa harus mendapatkan kompetensi yang tepat dalam bahasa apa pun yang mereka pelajari. ${ }^{25} \mathrm{Hal}$ ini penting agar kemurnian setiap bahasa dapat dipertahankan dan diwariskan kepada generasi penerus tanpa terdistorsi oleh bahasa dan dialek lain akibat kurangnya pengetahuan dan pemahaman. Ibn Khaldun sangat peduli untuk menyelamatkan bahasa Arab dari penyimpangan tersebut. ${ }^{26}$

c) Gagasan Pendidikan Ibn Khaldun di Dunia Kontemporer

Perekembangan pendidikan dewasa ini menantang kita untuk memikirkan sejauh mana gagasan pendidikan Ibn Khaldun dianggap relevan dan penting saat ini. Untuk menyelidiki persoalan ini, bukti masuknya gagasan pendidikan Ibn Khaldun dalam dokumen kontemporer pada kurikulum dan garis besar mata kuliah dalam program ilmu sosial, di berbagai belahan dunia, terutama yang terkait dengan pendidikan guru, perlu dicari. Kajian tentang Ibn Khaldun dan ide-idenya dapat ditemukan dalam mata kuliah sosiologi, ekonomi dan filsafat yang digunakan di sejumlah universitas dan lembaga pendidikan tinggi dan beberapa Madrasah Islam. ${ }^{27}$

Sejumlah karya cendekiawan kontemporer yang mengkaji gagasan pendidikan Ibnu Khaldun menjadi dasar makalah ini. Tiga di antaranya, yang berasal dari masyarakat Muslim dan non-Muslim, patut disebutkan. Dalam buku Ibn Khaldun: Life and Times, Allan James Fromberg (2011) membahas latar belakang pendidikan pribadi Ibn Khaldun dan pengalaman dari sudut pandang sejarah. Seorang sarjana Arab, Abdesselam Cheddadi, telah banyak menulis

\footnotetext{
${ }^{24}$ Alatas, 2012; Ibn Khaldun, 1958b

${ }^{25}$ Samarah, Y., A. (2011). Ibn Khaldun dan beberapa pandangan klasik dalam linguistik abad ke-

20. Teori dan praktek dalam studi bahasa, 1 (11), 1521-1530., h. 15-25

${ }^{26}$ Ibn Khaldun, 1958b; Samarah, 2011; Tjandrasasmita, 2006

${ }^{27}$ Tjandrasasmita, 2006
} 
PIWULANG: Jurnal Pendidikan Agama Islam, Vol. 3 No. 2 Maret 2021, 157-172

P-ISSN : 2622-5638. E-ISSN : 2622-5654

Homepage: http://e-journal.staima-alhikam.ac.id/index.php/piwulang

tentang gagasan pendidikan Ibn Khaldun, terutama dalam karyanya yang paling populer, Ibn Khaldun AD 1332 - 1406 / H 732 - 808 (1994). Pembahasan penting dan sangat rinci lainnya tentang gagasan pendidikan Ibnu Khaldun dapat ditemukan dalam buku karya Syed Farid Alatas (2012) yang berjudul The Makers of Islamic Civilization: Ibn Khaldun. Bab "Ibn Khaldun tentang Pendidikan dan Pengetahuan" memberikan penjelasan mendalam tentang ide-ide kunci dari Muqaddimah. Tak satu pun dari karya-karya ini, bagaimanapun, telah mempertimbangkan masuknya ide-ide pendidikan Ibn Khaldun dalam program pendidikan guru, baik di masyarakat Muslim maupun non-Muslim. Dalam dokumen tentang program pendidikan guru, penulis tidak menemukan bukti bahwa gagasan pendidikan Ibn Khaldun dimasukkan dalam pengajaran atau penelitian. Meskipun mungkin ada beberapa institusi di negara Muslim yang menggunakan idenya dalam program pendidikan guru atau dalam pengajaran sehari-hari, sedikit sekali referensi yang ditemukan untuk menunjukkan hal ini.

d) Kurikulum Program Pendidikan Guru di Hari Ini

Kita dapat mempertimbangkan lebih dekat, sebagai contoh kurikulum kontemporer untuk pendidikan guru. Dalam berbagai literatur yang membahas tentang kurikulum menjelaskan apa itu kurikulum dengan kembali ke ide-ide Yunani untuk asal-usul pandangan Barat tentang kurikulum, merujuk terutama pada ide-ide Plato dan Aristoteles. Tidak ada upaya yang dilakukan untuk mempertimbangkan ide-ide Timur seperti yang berasal dari Konfusius, Rabindranath Tagore, filosofi Ubuntu atau cendekiawan Buddha. Secara khusus, dari pendekatan tulisan ini, gagasan Ibn Khaldun dari tradisi Islam tidak disebutkan.

Penekanan Khaldun pada pentingnya mengembangkan ketrampilan berpikir dan penalaran siswa, kritiknya terhadap buku teks dengan penjelasan panjang dan terminologi yang rumit dan keyakinannya bahwa belajar harus menjadi pengalaman yang positif dan menyenangkan dapat berkontribusi dengan baik pada gagasan kurikulum kontemporer tentang mengembangkan ketrampilan kognitif dan berpikir kritis, dan memastikan bahwa pembelajaran berkontribusi pada rasa kesejahteraan siswa. Dimasukkannya perspektif yang beragam tersebut adalah salah satu cara untuk mengakui keragaman budaya siswa di sekolah-sekolah saat ini. 
PIWULANG: Jurnal Pendidikan Agama Islam, Vol. 3 No. 2 Maret 2021, 157-172

P-ISSN : 2622-5638. E-ISSN : 2622-5654

Homepage: http://e-journal.staima-alhikam.ac.id/index.php/piwulang

e) Kurikulum untuk Masyarakat Islam

Dalam Buku Induk Kebijakan Nasional Pembangunan Karakter Bangsa 2010-2025, pendidikan karakter memiliki tiga fungsi utama yaitu fungsi pembentukan dan pengembangan profesi, fungsi perbaikan dan penguatan, serta fungsi penyaring. ${ }^{28}$ Fungsi pembentukan dan pengembangan profesi berarti pendidikan karakter dilakukan untuk mengembangkan potensi setiap individu agar berpikiran baik, berhati baik, berperilaku baik sesuai dengan filsafat Pancasila. Fungsi perbaikan dan penguatan menekankan bahwa pendidikan karakter apat memperkuat peran keluarga, satuan pendidikan, masyarakat, dan pemerintah, untuk ikut berpartisipasi dan bertanggung jawab dalam pengembangan potensi warga negara dan pembangunan bangsa menuju bangsa yang maju, mandiri, dan sejahtera.

Sementara fungsi penyaring menekankan bahwa pendidikan karakter memiliki fungsi untuk memilah budaya bangsa sendiri dan menyaring budaya bangsa lain yang tidak sesuai dengan nilai budaya dan karakter bangsa yang bermartabat. Pendidikan karakter juga memiliki fungsi lain dalam membangun kehidupan kebangsaan yang multikultur, yaitu membangun peradaban bangsa yang cerdas, berbudaya luhur, dan mampu berkontribusi terhadap pengembangan kehidupan ummat manusia; mengembangkan potensi dasar agar berhati baik, berpikiran baik, berperilaku baik, dan keteladanan yang baik; serta membangun sikap warga negara yang cinta damai, kreatif, mandiri, dan mampu hidup berdampingan dengan bangsa lain dalam suatu harmoni. ${ }^{29}$

Meski demikian, dapat dikatakan bahwa cara terbaik untuk mendemonstrasikan nilai-nilai inklusif dari masyarakat adalah dengan memasukkan ide-ide dari seorang sarjana Islam seperti Ibn Khaldun dalam kurikulum kursus. Anjurannya tentang perjalanan sebagai sarana untuk memperoleh pengetahuan tentang orang lain dan budaya mereka serta memperluas pendidikan pribadi tampaknya paling tepat dalam konteks ini.

Prinsip Ibn Khaldun tentang pembelajaran bahasa yang benar juga relevan dalam konteks kontemporer. Pengelola sekolah dan guru di semua sistem perlu menyadari peran bahasa Arab

${ }^{28}$ Buku Induk Kebijakan Nasional Pembangunan Karakter Bangsa 2010-2025. Pemerintah Republik Indonesia. 2010. Jakarta

${ }^{29}$ Panduan Pelaksanaan Pendidikan Karakter Kementerian Pendidikan dan Kebudayaan, 2011 
PIWULANG: Jurnal Pendidikan Agama Islam, Vol. 3 No. 2 Maret 2021, 157-172

P-ISSN : 2622-5638. E-ISSN : 2622-5654

Homepage: http://e-journal.staima-alhikam.ac.id/index.php/piwulang

sebagai bahasa Al-Qur'an, kitab suci agama Islam. Pada usia dini, banyak anak Islam belajar bahasa Arab selain bahasa di rumah. Bahasa Arab modern yang digunakan di Suriah, Yordania, Lebanon, dan Irak saat ini berbeda dengan bahasa Arab abad keenam dalam Al-Qur'an; Iran, Afghanistan, Pakistan, dan Uighur, misalnya, memiliki bahasa (atau bahasa) khusus mereka sendiri untuk digunakan dalam kehidupan sehari-hari dalam keluarga dan masyarakat. Guru perlu memahami dan memperhitungkan hal ini dalam pengajaran di kelas mereka.

Pentingnya pendekatan inklusif terhadap kurikulum pendidikan guru di sekolah telah disoroti oleh Bowering dan Lock (2007). ${ }^{30}$ Mereka mengklaim bahwa hal ini diperlukan jika ingin serius mengadopsi kurikulum yang lebih berorientasi internasional daripada Eurosentris. Hal ini khususnya relevan dengan komunitas Islam di Indonesia yang memiliki proporsi siswa muda yang tinggi dan semakin banyak yang mendirikan sekolah Islam independen mereka sendiri.

Hampir 90\% pemuda Muslim bersekolah di sekolah negeri setempat (Welch, 2013), di mana mereka kemungkinan besar akan diajar oleh guru yang minim pemahaman ajaran Islam, sangat sedikit dari mereka yang memiliki kesempatan untuk memahami agama Islam, budaya dan nilai-nilai pendidikan Islam. Namun sekolah Islam sendiri juga bertambah jumlahnya. Mereka sering merekrut guru umum untuk mengampu mata pelajaran utama dalam kurikulum, tetapi mereka juga berusaha merekrut guru berpendidikan pesantren sebagai spesialis agama yang memiliki kualifikasi pendidikan guru. Dengan demikian, ada dua bidang kebutuhan terkait dengan program pendidikan guru di Indonesia: sekolah umum maupun sekolah Islam membutuhkan guru-guru tetap yang memiliki pengetahuan dan pemahaman Islam yang inklusif agar responsif terhadap tradisi dan budaya dalam mengajar siswa di kelas mereka. Pada saat yang sama, ada siswa pendidikan guru dengan latar belakang Islam yang mengindikasikan bahwa mereka ingin lebih banyak pengetahuan budaya mereka dimasukkan ke dalam pelajaran mereka. Pendekatan kurikulum seperti itu berpotensi untuk melihat gagasan pendidikan Ibn Khaldun dimasukkan ke dalam program pendidikan guru di Indonesia.

${ }^{30}$ Bowering, M., \& Lock, G. (2007). A cross-cultural teacher training program for Singaporean Muslim Students. Australian Journal of Teacher Education, 32(3), 14-26.

- $\quad$ Mutamakin \& M. Yusuf Agung- 170 
PIWULANG: Jurnal Pendidikan Agama Islam, Vol. 3 No. 2 Maret 2021, 157-172

P-ISSN : 2622-5638. E-ISSN : 2622-5654

Homepage: http://e-journal.staima-alhikam.ac.id/index.php/piwulang

\section{KESIMPULAN}

Pembahasan tentang filsafat pendidikan dan klasifikasi ilmu pengetahuan Ibnu Khaldun, serta gagasannya tentang belajar mengajar dan kurikulum, mengungkapkan bahwa isu-isu yang ia diskusikan dalam konteks dunia Islam abad ke-14 sangat mirip dengan yang ada saat ini. Meski dengan latarbelakang zaman berbeda, gagasannya masih relevan dengan kurikulum berorientasi global pada abad ke-21. Dalam pengertian ini, tulisannya tentang pendidikan dapat dilihat memiliki makna universal lintas abad dan lintas budaya.

Makalah ini menunjukkan bahwa nama Ibn Khaldun dan kesadaran akan kontribusinya terhadap filsafat dan praktik pendidikan hanya difahami oleh kalangan ilmuwan tertentu. Mereka adalah spesialis di dunia pembelajaran Arab abad pertengahan atau sarjana di universitas Islam, yang telah menafsirkan ulang pentingnya gagasan pendidikan Ibn Khaldun dalam kaitannya dengan dunia kontemporer. Sebaliknya, di negara-negara dunia Barat, tidak ada bukti gagasan pendidikan Ibnu Khaldun dimasukkan ke dalam program pendidikan guru. Apakah pengabaian komparatif terhadap Ibn Khaldun dalam teori pendidikan dunia Barat saat ini adalah hasil dari biner geografis yang dijelaskan oleh Connell, di mana Ibn Khaldun dianggap sebagai seorang sarjana dari Selatan, yang sebagian besar diabaikan oleh komunitas akademis Ortodoks di Utara? Ataukah relevan untuk juga memperhitungkan perbedaan budaya dan bahasa yang telah berkontribusi pada pengesampingan peran Ibn Khaldun di dunia kontemporer? Saat ini, konseptualisasi pendidikan dan pembelajaran berkiblat terutama di dunia Barat yang secara nominal beragama Kristen, sebagian besar berbahasa Inggris daripada dunia berbahasa Arab Islam di Selatan, seperti yang terjadi selama Abad Pertengahan.

Pertimbangan beberapa aspek kurikulum yang dapat ditemukan dalam program pendidikan guru di Indonesia menunjukkan kemungkinan mengembangkan pendekatan inklusif terhadap kurikulum. Pendekatan ini tampaknya menjadi sangat tepat dalam masyarakat majemuk seperti di Indonesia. Dalam kurikulum inklusif, pengetahuan tentang gagasan pendidikan Ibn Khaldun akan dipandang penting bagi siswa. Mereka yang berlatar belakang Islam akan mendapatkan bagian dari warisan budaya mereka yang diakui dalam kurikulum sekolah-sekolah, dengan cara yang secara positif dapat menegaskan identitas dan tempat mereka di Indonesia. Sama halnya, semua warga lainnya, tanpa memandang latar belakang suku dan budaya, akan dapat memahami kontribusi penting dari pengetahuan yang dibawa komunitas Islam kepada seluruh warga negara Indonesia. 
PIWULANG: Jurnal Pendidikan Agama Islam, Vol. 3 No. 2 Maret 2021, 157-172

P-ISSN : 2622-5638. E-ISSN : 2622-5654

Homepage: http://e-journal.staima-alhikam.ac.id/index.php/piwulang

\section{DAFTAR RUJUKAN}

Alatas, S., F. (2007). The historical sociology of Muslim societies: Khaldunian applications. International Sociology, 22(3), 267-288.

Alatas, S., F. (2012). Makers of Islamic Civilization: Ibn Khaldun New Delhi: Oxford University Press.

Alatas, S., H. (2006). The autonomous, the universal and the future of sociology. Current Sociology, 54(1), 112-132.

Brady, L., \& Kennedy, K. (2014). Curriculum Construction (5th ed.). Frenchs Forest: Pearson.

Buku Induk Kebijakan Nasional Pembangunan Karakter Bangsa 2010-2025. Pemerintah Republik Indonesia. 2010. Jakarta

Ibn Khaldun. (1958a). The 'Muqaddimah': An Introduction to History, terjemah dari bahasa Arab oleh Rosenthal, F (Vol. I). London: Routledge \& Kegan Paul.

Ibn Khaldun. (1958b). The 'Muqaddimah': An Introduction to History, terjemah dari bahasa Arab oleh Rosenthal, F (Vol. VI). London: Routledge \& Kegan Paul.

Irwin, R. (1996). Munculnya Sistem Dunia Islam 1000-1500M. Dalam F. Robinson (Ed.), Cambridge Illustrated History of the Islamic World (hlm. 32-61). Cambridge: Cambridge University Press.

Panduan Pelaksanaan Pendidikan Karakter, Kementerian Pendidikan dan Kebudayaan, 2011

Robinson, F. (1996). Knowledge its transforming the making of Muslim societies In F. Robinson (Ed.), The Cambridge illustrated history of the Islamic world. Cambridge, England Cambridge University Press.

Samarah, Y., A. (2011). Ibn Khaldun dan beberapa pandangan klasik dalam linguistik abad ke-20. Teori dan praktek dalam studi bahasa, 1 (11), 1521-1530.

Tjandrasasmita, U. (2006). Kajian naskah-naskah sejarah klasik dan penerapannya bagi kajian Islam di Indonesia. Jakarta: Puslitbang Lektur Keagamaan. 